\title{
Association among Working Hours, Occupational Stress, and Presenteeism among Wage Workers: Results from the Second Korean Working Conditions Survey
}

\author{
Sung-Hwan Jeon, Jong-Han Leem, Shin-Goo Park, Yong-Seok Heo, Bum-Joon Lee, So-Hyun Moon,
} Dal-Young Jung and Hwan-Cheol Kim*

\begin{abstract}
Objectives: The purpose of the present study was to identify the association between presenteeism and long working hours, shiftwork, and occupational stress using representative national survey data on Korean workers.

Methods: We analyzed data from the second Korean Working Conditions Survey (KWCS), which was conducted in 2010, in which a total of 6,220 wage workers were analyzed. The study population included the economically active population aged above 15 years, and living in the Republic of Korea. We used the chi-squared test and multivariate logistic regression to test the statistical association between presenteeism and working hours, shiftwork, and occupational stress.

Results: Approximately 19\% of the workers experienced presenteeism during the previous 12 months. Women had higher rates of presenteeism than men. We found a statistically significant dose-response relationship between working hours and presenteeism. Shift workers had a slightly higher rate of presenteeism than non-shift workers, but the difference was not statistically significant. Occupational stress, such as high job demand, lack of rewards, and inadequate social support, had a significant association with presenteeism.
\end{abstract}

Conclusions: The present study suggests that long working hours and occupational stress are significantly related to presenteeism.

Keywords: Presenteeism, Occupational stress, Working hours, Shift work

\section{Introduction}

Workers' health is not only their own issue, but also an important issue for their employers. The illness of workers can result in lost workforce productivity and add to the disease burden of the company or community. One study found that estimated costs of health-related productivity loss were significantly greater than medical and pharmacy costs [1]. Generally, productivity loss due to workers' poor health arises from absenteeism or presenteeism. Absenteeism, which is the easily understandable concept of absence from work due to disease, places a well-known economic burden on industry. In contrast, presenteeism is a newer

\footnotetext{
* Correspondence: carpediem@inha.ac.kr

Department of Occupational and Environment Medicine, School of Medicine, Inha University, Incheon, South Korea
}

economic concept and has recently been recognized as a health problem in the workplace.

Presenteeism is defined as being present at work, but limited in some aspects of job performance by a health problem [2]. Working while sick can lead to many negative consequences, such as lost productivity, reduced work team cohesion, accidents, job insecurity/turnover, worsening health, and longer recovery time [3]. The economic burden of presenteeism has been overlooked because it is not as obvious to employers or workers as the economic costs due to absenteeism. However, according to the Harvard Business Review, the estimated total cost of presenteeism in the United States was more than $\$ 150$ billion per year, and the economic cost of presenteeism was far more than that of absenteeism or disability [4]. 
Sickness presenteeism can also be a risk factor for other adverse health events. Sickness absenteeism provides time for a recovery period and appropriate medical management to ill and distressed workers. However, workers who work while sick can not resolve their unhealthy condition and could be faced with a cumulative stress burden. In a recent report based on a cohort of male British civil servants, unhealthy employees who took no absence during a 3-year follow-up had a 2-fold higher incidence rate of serious coronary events than unhealthy employees with a moderate level of sickness absenteeism [5]. Several other studies have also suggested that sickness presenteeism predicts poor selfrated health and future sickness absence [6-8].

The risk factors for presenteeism include both physical and psychological health conditions [1,9-11]. According to a prospective study of about employees of a financial services company, 10 health risk factors (cigarette smoking, physical activities, safety belt use, use relaxation medicine, high blood pressure, obesity, life dissatisfaction, job dissatisfaction, perception of physical health, and high stress) were significantly correlated with presenteeism [12].

In general, long working hours, shift work and occupational stress can exacerbate workers' chronic health conditions. Long working hours, shift work, and occupational stress lead to unhealthy habits, such as smoking, alcohol abuse, lack of physical activity, sleeplessness, poor eating habits, and fewer chances for medical examinations, consequently aggravating physical conditions [13]. Recent research suggesting long working hours is associated with increased BMI and waist circumference [14], poorer lifestyle, higher stress, and lower quality of life [15], high blood pressure [16], and cardiovascular disease $[17,18]$. Shift work is associated with occurrence of obesity, dyslipidemia, and metabolic syndrome $[19,20]$, and a higher risk for common infections [21]. Shift work can act as an oxidative stressor and may induce many medical disorders [22]. Association between occupational stress and adverse health outcomes was also supported by many studies. Occupational stress is associated with migraine [23], high blood pressure [24] and coronary heart disease [5,25,26], psychiatric disorders [27-30], such as depression and anxiety. Other research has suggested the association of occupational stress and unhealthy behaviours [31,32], such as smoking and obesity.

Therefore, we hypothesize that those work-related health risk factors (long working hours, shift work, and occupational stress) have a significant association with presenteeism. In fact, some studies suggesting an association between work-related hazardous factors and presenteeism have been conducted [33,34], but no previous investigation has used large-scale representative data from a Korean population.
Hence, the aim of this study was to identify the association between presenteeism and long working hours, shiftwork, and occupational stress using large-scale representative data from the second Korean Working Conditions Survey (KWCS).

\section{Materials and methods Study population}

We analyzed data from the second KWCS, which was conducted in 2010, to identify the statistical association between working conditions (occupational stress, work hours, and shift work) and presenteeism. The aim of the KWCS was to identify rates and causes of work-related diseases and accidents, and to verify the effect of mechanical, physical, and chemical hazards in the workplace and psychosocial factors that influence working conditions. The population of the KWCS included the economically active population of those 15 years of age and above who live in Korea. 10,019 participants responded to the questionnaire. We restricted the population of this study to wage workers, and thus 6,220 participants were included. The study population was weighted by the size of a family based on 2011 census of Korea (sum of weights $=7,112$ ).

\section{Variables \\ General characteristics}

To identify the influence of the study population's general characteristics on presenteeism, we obtained information regarding demographic and behavioral characteristics (age, sex, educational status, smoking status, alcohol consumption, obesity, depressive symptoms, and history of hypertension) and work-related characteristics (employment status, job type, number of employees, tenure). We classified smoking status into non-smoker, ex-smoker, and current smoker, and alcohol consumption into non-drinker, once per week or less, and twice or more per week. The job types were classified into three categories: white collar, blue collar, and service workers.

\section{Workplace environmental risk exposure}

We divided workplace environmental risk exposure into three categories: (i) physical risk exposure (vibration, noise, high temperature, low temperature, mist, dust, fumes), (ii) biological/chemical risk exposure (organic solvents, chemical agents, secondhand smoke, infectious agents), and (iii) ergonomic risk exposure (painful or tiring positions, repetitive hand or arm movements, moving or lifting people, heavy loads, standing posture). Workplace environmental risk exposures were classified as dichotomous variables (exposed or unexposed). The population exposed to physical, biological/chemical, and ergonomic risks was defined as those who were exposed 
to at least one of sub-factors of each of the environmental risk factors during $1 / 4$ or more of their working time.

\section{Working hours and shiftwork}

Working hours were identified using the following question: "How many hours do you work in a week in your workplace (excluding commuting and meal time)?" Working hours were rounded off to the nearest hour. According to the Korean Labor Standards Act, working hours per week shall not exceed 40 hours excluding break times. If the parties concerned reach agreement, the working hours may be extended by up to twelve hours per week [35]. According to the Enforcement Decree of the Industrial Accident Compensation Insurance Act of Republic of Korea, chronic overwork was defined as exceeding 6 working hours per week for 3 months. Therefore, we categorized working hours as (i) $\leq 40$ hours, (ii) $41-52$ hours, (iii) 53-60 hours, and (iv) $>60$ hours. We defined non-shift workers as those who usually work during the daytime, and the others were classified as shift workers.

\section{Occupational stress}

Variables about occupational stress were classified and reduced by using the method from "Secondary analysis of Korean working conditions survey: Causes of absenteeism due to disease in employed women" by Kim JE [36]. To measure occupational stress in the workplace, we used five sections: (i) high job demand, (ii) insufficient job control, (iii) inadequate social support, (iv) job insecurity, and (v) lack of rewards. Seven items (rapid speed of work, strict deadlines, interruption of work due to unexpected new tasks, strict standard of quality, selfassessment of work, self-problem solving of unexpected events, insufficient time to work) were used to evaluate high job demand. Seven items (able to spend time handling private or familial tasks during business hours, able to choose or change the order of tasks, able to choose or change methods of work, able to choose or change the speed of work, influence over choice of working partners, able to take a break when desired, influence over making important decisions in tasks) were used to evaluate insufficient job control. Eight items (social support of coworkers, social support of superiors, having very good friends at the workplace, feedback on work by superiors, respect for personality, ability to resolve a conflict, ability to plan or organize work, encouragement to join in important decision making) were used to evaluate inadequate social support. Job insecurity was evaluated using the following 2 questions: (i) "I might lose my job in the next 6 months." and (ii) "If I leave or lose my current job, I can easily find a new job with the same payment." Lack of rewards was evaluated using the following question: "I am well paid for the work I do." Each section was converted to a dichotomous variable (high/ low) according to the median value. The Cronbach's $\alpha$ of each section were: (i) 0.639 (high job demand), (ii) 0.680 (insufficient job control), (iii) 0.775 (inadequate social support).

\section{Presenteeism}

Presenteeism was identified using the following question: "Over the past twelve months, have you been working, even if you were sick?"

\section{Statistical analysis}

The chi-squared test was applied to identify the statistical association between presenteeism and the possible confounding variables. Univariate and multivariate logistic regression were used to test the statistical association of presenteeism and working hours, shiftwork, and occupational stress. We calculated the odds ratios (ORs) and 95\% confidence interval (95\% CI) in two models: (i) Model I: crude ORs, (ii) Model II: adjusted by general characteristics and workplace environmental risk exposure (age, gender, education, smoking status, hypertension, obesity, depressive symptoms, job type, tenure, and physical, biological/chemical, and ergonomic risk exposure). Variables for general characteristics whose univariate test had a p-value $<0.05$ were defined as confounding variables and included in Model II as covariates. We used Statistical Package for the Social Sciences software (SPSS version 14.0; SPSS, Inc., Chicago, IL, USA) to conduct the statistical analysis.

\section{Results}

\section{Demographic and work-related characteristics}

In this study, there were more male participants (58.8\%) than female participants (41.2\%). The mean age was 40.53 years, ranging from 15 to 83 .

The associations between general characteristics and presenteeism are shown in Table 1. 1,341 workers (18.9\%) had experienced presenteeism. The females $(22.2 \%)$ had a significantly higher experience rate than males (16.5\%). There was a high correlation between hypertension ( $\mathrm{p}$-value $<0.001)$, obesity ( $\mathrm{p}$-value $<0.001)$, depressive symptoms ( $\mathrm{p}$-value $<0.001$ ), and presenteeism. Service workers $(16.5 \%)$ had a significantly lower experience rate than white collar workers $(19.7 \%)$ or blue collar workers (19.1\%). New employees (14.8\%), who had tenure of less than a year, had a significantly lower experience rate. Regular workers (19.2\%) showed a slightly higher rate of presenteeism than temporary workers (18.2\%), but there was no statistical significance (p-value $=0.291)$. Those who were exposed to physical or biological/chemical risk factors had a significantly higher rate of experiencing presenteeism than the non-exposure group (p-value $<0.001$ ). Those who were exposed to ergonomic risk factors showed a slightly higher experience rate 
Table 1 The relationship between general characteristics, work-related factors, and presenteeism

\begin{tabular}{|c|c|c|c|c|c|}
\hline & \multirow[b]{2}{*}{$\mathrm{N} \dagger$} & \multirow[b]{2}{*}{$\%$} & \multicolumn{2}{|c|}{ Presenteeism } & \multirow[b]{2}{*}{ p-value* } \\
\hline & & & $\mathrm{n}$ & $\%$ & \\
\hline \multicolumn{6}{|l|}{ Gender } \\
\hline Female & 2928 & 41.2 & 649 & 22.2 & $<0.001$ \\
\hline Male & 4184 & 58.8 & 692 & 16.5 & \\
\hline \multicolumn{6}{|l|}{ Age } \\
\hline$<30$ & 1481 & 20.8 & 219 & 14.8 & $<0.001$ \\
\hline $30-39$ & 2057 & 28.9 & 404 & 19.6 & \\
\hline $40-49$ & 1880 & 26.4 & 386 & 20.5 & \\
\hline $50-59$ & 1155 & 16.2 & 225 & 19.5 & \\
\hline$\geq 60$ & 539 & 7.6 & 107 & 19.8 & \\
\hline \multicolumn{6}{|l|}{ Educational status } \\
\hline$<$ Middle school & 973 & 13.7 & 212 & 21.8 & 0.004 \\
\hline High school & 2966 & 41.7 & 512 & 17.3 & \\
\hline$>$ College & 3172 & 44.6 & 616 & 19.4 & \\
\hline \multicolumn{6}{|l|}{ Smoking } \\
\hline non-smoker & 3884 & 54.6 & 790 & 20.3 & 0.002 \\
\hline ex-smoker & 697 & 9.8 & 114 & 16.4 & \\
\hline smoker & 2531 & 35.6 & 436 & 17.2 & \\
\hline \multicolumn{6}{|l|}{ Drinking frequency } \\
\hline none & 1938 & 27.2 & 378 & 19.5 & 0.473 \\
\hline$\leq 1$ per week & 2965 & 41.7 & 564 & 19.0 & \\
\hline$\geq 2$ per week & 2209 & 31.1 & 399 & 18.1 & \\
\hline \multicolumn{6}{|l|}{ Hypertension } \\
\hline No & 6622 & 93.1 & 1198 & 18.1 & $<0.001$ \\
\hline Yes & 489 & 6.9 & 143 & 29.2 & \\
\hline \multicolumn{6}{|l|}{ Obesity } \\
\hline No & 6886 & 96.8 & 1254 & 18.2 & $<0.001$ \\
\hline Yes & 226 & 3.2 & 87 & 38.5 & \\
\hline \multicolumn{6}{|l|}{ Depressive symptoms } \\
\hline No & 6999 & 98.4 & 1272 & 18.2 & $<0.001$ \\
\hline Yes & 112 & 1.6 & 68 & 60.7 & \\
\hline \multicolumn{6}{|l|}{ Employment status } \\
\hline Regular & 4568 & 64.2 & 878 & 19.2 & 0.291 \\
\hline Temporary & 2544 & 35.8 & 463 & 18.2 & \\
\hline \multicolumn{6}{|l|}{ Job type } \\
\hline White collar & 3081 & 43.3 & 606 & 19.7 & 0.043 \\
\hline Service & 1350 & 19.0 & 223 & 16.5 & \\
\hline Blue collar & 2680 & 37.7 & 511 & 19.1 & \\
\hline \multicolumn{6}{|l|}{ Number of employees } \\
\hline$<5$ & 1526 & 22.3 & 285 & 18.7 & 0.088 \\
\hline $5-49$ & 3295 & 48.4 & 599 & 18.2 & \\
\hline $50-299$ & 1315 & 19.3 & 246 & 18.7 & \\
\hline$\geq 300$ & 689 & 10.0 & 157 & 22.8 & \\
\hline
\end{tabular}

Table 1 The relationship between general characteristics, work-related factors, and presenteeism (Continued)

Tenure (yr)

$\begin{array}{llllll}<1 & 1477 & 20.8 & 218 & 14.8 & <0.001 \\ 1-10 & 4084 & 57.4 & 826 & 20.2 & \\ \geq 10 & 1550 & 21.8 & 296 & 19.1 & \end{array}$

Physical risk exposure

$\begin{array}{rlllll}\text { Unexposed } & 4348 & 61.1 & 745 & 17.1 & <0.001 \\ \text { Exposed } & 2764 & 38.9 & 596 & 21.6 & \end{array}$

Biological/chemical risk exposure

$\begin{array}{rlllll}\text { Unexposed } & 5126 & 72.1 & 887 & 17.3 & <0.001 \\ \text { Exposed } & 1985 & 27.9 & 453 & 22.8 & \end{array}$

Ergonomic risk exposure

\begin{tabular}{rrrrrr} 
Unexposed & 1541 & 21.7 & 264 & 17.1 & 0.052 \\
Exposed & 5569 & 78.3 & 1076 & 19.3 & \\
\hline
\end{tabular}

*Based on the chi-squared test.

†All numbers reflect weighted frequencies.

than the non-exposure group, but the difference was not statistically significant $(\mathrm{p}$-value $=0.052)$.

\section{Working hours, shift work, occupational stress and presenteeism}

The univariate analysis of work-related hazardous factors and presenteeism is shown in Table 2. The group who worked $>60$ hours per week (27.5\%) showed the highest rate of presenteeism, followed by those who worked 5360 hours per week (20.7\%), 41-52 hours per week $(19.2 \%)$, and $\leq 40$ hours per week (16.6\%). Shift workers (20.2\%) had a slightly higher rate of presenteeism than non-shift workers $(18.7 \%)$, but the difference was not statistically significant ( $\mathrm{p}$-value $=0.328$ ). Job stressors, such as high job demand, inadequate social support, and lack of reward, had strong associations with presenteeism $(\mathrm{p}$-value $<0.001, \mathrm{p}$-value $=0.046, \mathrm{p}$-value $<0.001)$, but insufficient job control and job insecurity did not have a significant association.

The multivariate analysis of work-related hazardous factors and presenteeism is shown in Table 3.

Working for long hours was a significant risk factor of presenteeism in all of the models. Compared with the reference group who worked $\leq 40$ hours per week, the ORs for those working $>60$ hours, 53-60 hours, and 4152 hours per week were 1.898 (95\% CI 1.549-2.325), 1.306 (95\% CI 1.096-1.556), and 1.192 (95\% CI 1.034 1.373 ) in model I; and 2.098 (95\% CI 1.686-2.611), 1.480 (95\% CI 1.230-1.783), and 1.192 (95\% CI 1.030-1.380) in model II, respectively. We also found a dose-response relationship between working hours and presenteeism in all models ( $\mathrm{p}$ for trend $<0.001$ ). We were able to identify a statistically significant association between shift work 
Table 2 The relationship between working hours, shiftwork, occupational stress, and presenteeism

\begin{tabular}{rrrrrrr}
\hline & & & \multicolumn{3}{c}{ Presenteeism } \\
\cline { 6 - 8 } & N† & $\%$ & No & $\%$ & p-value* \\
\hline Working Time (hr/wk) & & & & & \\
$\leq 40$ & 3438 & 48.3 & 148 & 16.6 & $<0.001$ \\
$41-52$ & 2056 & 28.9 & 814 & 19.2 & \\
$53-60$ & 1035 & 14.6 & 79 & 20.7 & \\
$>60$ & 582 & 8.2 & 299 & 27.5 &
\end{tabular}

Shift work

\begin{tabular}{rrrrrrr} 
& No & 6337 & 89.1 & 1185 & 18.7 & 0.328 \\
& Yes & 774 & 10.9 & 156 & 20.2 & \\
High job demand & & & & & & \\
\cline { 2 - 7 } & Low & 5332 & 75.0 & 854 & 16.0 & $<0.001$ \\
& High & 1779 & 25.0 & 487 & 27.4 &
\end{tabular}

Insufficient job control

$\begin{array}{lllll}\text { Low } & 4118 & 57.9 & 804 & 19.5 \\ \text { High } & 2993 & 42.1 & 536 & 17.9\end{array}$

Inadequate social support

\begin{tabular}{lcccccc} 
& Low & 3752 & 52.7 & 674 & 18.0 & 0.046 \\
& High & 3360 & 47.3 & 666 & 19.8 & \\
Job insecurity & & & & & & \\
& Low & 2963 & 41.8 & 573 & 19.3 & 0.363 \\
& High & 4127 & 58.2 & 763 & 18.5 & \\
Lack of reward & & & & & & \\
& Low & 4265 & 60.1 & 743 & 17.4 & $<0.001$ \\
& High & 2831 & 39.9 & 595 & 21.0 & \\
\hline
\end{tabular}

*Based on the chi-squared test.

†All numbers reflect weighted frequencies.

and presenteeism in model II, but model I did not show statistical significance $(\mathrm{OR}=1.098,95 \%$ CI $0.911-1.323$ in Model I; OR $=1.221,95 \%$ CI 1.001-1.461 in Model II).

The results on the associations of presenteeism and occupational stress were significant in three sections. High job demand was the most powerful stressor that induced presenteeism. The ORs for high job demand were 1.977 (95\% CI 1.741-2.246) and 1.822 (95\% CI 1.588-2.091) in each of the two models, respectively. We also found statistically significant associations between presenteeism and lack of rewards and inadequate social support. However, negative associations with job insecurity and insufficient job control were shown, but they were not statistically significant.

\section{Discussion}

In this study, we identified associations between presenteeism and work-related hazardous factors by using large-scale representative data from the Korean working population. We found a strong association between
Table 3 The odds ratios and $95 \%$ confidence intervals of working hours, shiftwork, and occupational stress on presenteeism

\begin{tabular}{|c|c|c|c|c|}
\hline & \multicolumn{2}{|c|}{ Model I* } & \multicolumn{2}{|c|}{ Model IIt } \\
\hline & OR & $95 \% \mathrm{Cl}$ & OR & $95 \% \mathrm{Cl}$ \\
\hline \multicolumn{5}{|l|}{ Working Time (hr/wk) } \\
\hline$\leq 40$ & 1.00 & & 1.00 & \\
\hline $41-52$ & 1.19 & $1.03-1.37$ & 1.19 & $1.03-1.38$ \\
\hline $53-60$ & 1.31 & $1.10-1.56$ & 1.48 & $1.23-1.78$ \\
\hline$>60$ & 1.90 & $1.55-2.33$ & 2.10 & $1.69-2.61$ \\
\hline \multicolumn{5}{|l|}{ Shift work } \\
\hline No & 1.00 & & 1.00 & \\
\hline Yes & 1.10 & $0.91-1.32$ & 1.22 & $1.00-1.46$ \\
\hline \multicolumn{5}{|l|}{ Occupational stress } \\
\hline \multicolumn{5}{|l|}{ High job demand } \\
\hline Low & 1.00 & & 1.00 & \\
\hline High & 1.98 & $1.74-2.25$ & 1.82 & $1.59-2.09$ \\
\hline \multicolumn{5}{|l|}{ Insufficient job control } \\
\hline Low & 1.00 & & 1.00 & \\
\hline High & 0.90 & $0.80-1.02$ & 0.93 & $0.82-1.05$ \\
\hline \multicolumn{5}{|l|}{ Inadequate social support } \\
\hline Low & 1.00 & & 1.00 & \\
\hline High & 1.13 & $1.00-1.27$ & 1.10 & $0.97-1.26$ \\
\hline \multicolumn{5}{|l|}{ Job insecurity } \\
\hline Low & 1.00 & & 1.00 & \\
\hline High & 0.95 & $0.84-1.07$ & 0.92 & $0.81-1.04$ \\
\hline \multicolumn{5}{|l|}{ Lack of reward } \\
\hline Low & 1.00 & & 1.00 & \\
\hline High & 1.26 & $1.12-1.42$ & 1.23 & $1.08-1.39$ \\
\hline
\end{tabular}

${ }^{*}$ Crude odds ratio.

†Adjusted for age, gender, education, smoking status, hypertension, obesity, depressive symptoms, job type, tenure, and physical, biological/chemical, and ergonomic risk exposure.

presenteeism and chronic health conditions, such as a history of hypertension, obesity, and depressive symptoms. This result suggests that sickness presenteeism could be induced by a worker's chronic health condition. This hypothesis is supported by recent studies. Mental and physical disorders are associated with additional days of absence and reduced qualitative functioning at work $[9,11]$. Chronic health conditions, such as depression, anxiety, sleep problems, fatigue, obesity, arthritis, headache, and back/neck pain, are significantly related to absenteeism and presenteeism [1,10]. According to our results, workplace environmental risk exposure was significantly related to presenteeism, except ergonomic risk exposure ( $\mathrm{p}$-value $=0.052$ ). There is a lack of research about the association between presenteeism and workplace environmental risk exposure. However, a variety of workplace environmental risks, such as heavy 
physical work load, ergonomic conditions, and hazardous exposure, have been found to be associated with sicknessabsence [37,38]. Furthermore, workplace environmental risk exposure may induce many medical disorders. Consequently, hazardous exposures in the workplace are likely to be related to presenteeism.

We also found a significant relationship between working hours and presenteeism. In particular, those who worked over 60 hours per week had a 2-fold higher odds ratio than those who worked 40 or less hours per week. Respondents working $>60$ hours had highest odds ratio, followed by 53-60 hours and 41-52 hours. We conducted a trend analysis and found a statistically significant result ( $\mathrm{p}$ for trend $<0.001$ ). This finding suggests a doseresponse relationship between working hours and presenteeism. Our finding of significant relationship between working hours and presenteeism can be explained by the adverse health effects of long working hours. Several studies have suggested that long working hours can be a risk for adverse health events. Those include cardiovascular disease $[5,25,26]$, metabolic disease, such as metabolic syndrome [39], hypertension [40], obesity [41], and mental disorders such as sleep disturbance [42], depression [43], and anxiety [44]. Those chronic health conditions are associated with presenteeism [1] and loss of productivity [9]. Moreover, sleep disturbance and fatigue due to long work hours especially increase the risk of injury and accidents on the job [45], and decrease productivity by reducing job performance [46].

Shift work causes disturbances of the normal circadian rhythms; consequently, shift workers suffer from socalled 'shift-lag' syndrome, which is characterized by feelings of fatigue, sleepiness, insomnia, disorientation, digestive troubles, irritability, poorer mental agility, and reduced performance efficiency [47]. Consequently, shift work also can be a risk factor of presenteeism. A Finnish study reported a relationship between presenteeism and shift work, but they did not find statistical significance [48]. In this study, shift workers showed a bit higher experience rate of presenteeism than non-shift workers, and we were able to find a significant association in the adjusted model. The Republic of Korea shows higher proportions of shift workers in the service sector [49]. Therefore, our analysis using overall population could not identify an effect in the highly exposed group. We anticipate further research about the influence of shift work on presenteeism within highly exposed populations.

Our study suggests that high job demand was the most important risk factor of presenteeism among the job stressors. Lack of rewards also had a significant association with presenteeism. However, insufficient job control and job insecurity had a negative correlation, but this was not statistically significant. Psychosocial working conditions have a strong relationship with workers' general health condition and productivity. Job stressors such as job demand, interpersonal conflict, and lack of reward are correlated with absence and early leave from work [50]. Workers experiencing high job demands and a low decision latitude, job strain, and low social support show a high risk of long-term illness [51]. Consequently, presenteeism also closely associated with occupational stress $[34,52]$. According to a study of Boles et al., employees with high stress reported $10.2 \%$ presenteeism compared with $5.0 \%$ presenteeism among those who did not have high stress [53]. Another study suggests that with higher levels of job stress, sickness presenteeism occurred more often than sickness absence [54].

A high job demand had been identified as a risk factor for presenteeism in recent studies. Job demand leads to presenteeism and burnout [55]. Burnout has a reciprocal relationship with presenteeism since emotional exhaustion leads to presenteeism, which in turn causes more exhaustion later on [55]. Highly demanding occupations usually involve great responsibility for tasks or clients. Fewer no substitutes for workers, high workloads, and inflexible deadlines make workers feel pressure to attend. Therefore, those pressures or responsibilities lead workers with high job demands to work while sick. For example, occupations that have strong attendance demands such as medicine, nursing, and welfare and teaching occupations have a greater risk of presenteeism [56]. Similarly, difficulty in staff replacement and time pressure can be risks for presenteeism [57].

In this study, 'lack of reward' was defined as discontent with wages. The association of presenteeism and lack of reward can be explained by financial distress due to an unsatisfactory wage. Workers with an unsatisfactory wage, cannot easily afford to be absent from work because of their financial distress. Consequently, they are present at work even if they are sick. Along these lines, occupations with high sickness presenteeism are associated with a low monthly income [56].

The negative association between job insecurity and presenteeism may be explained by workers' morale. Loyalty to the team and a work ethic have been mentioned as reasons to go to work ill $[58,59]$. However, job insecurity lowers a worker's morale, which is associated with loyalty and a work ethic. The nature of their task, which is replaceable by a substitute, may reduce their sense of responsibility toward their duties.

Our study has some limitations. First, there is a potential mis-estimation of the experience rate of presenteeism by using a self-administered questionnaire. The participants' answers could have been subjective. In addition, misclassification due to uncertainty of participants' memory also can not be excluded. This misclassification can 
cause attenuation of statistical associations. Second, we identified associations between work-related hazardous factors and presenteeism, but could not determine the direction of causality or any temporal relationship because of the nature of a cross-sectional research design. To identify the causality, further prospective evaluation will be needed. Finally, the Cronbach's $\alpha$ of high job demand and insufficient job control were not enough to expect satisfactory reliability.

In spite of these limitations, our study also has strengths and significance. First, the KWCS is the most comprehensive national survey about workers' health and working conditions in Korea. Our study was conducted using this representative data, so the results can be considered reliable. Second, our study comprehensively analyzed workrelated hazards, including workplace environmental risk exposure, long working hours, shiftwork, and occupational stress. Some studies suggesting an association between work-related factors and presenteeism have been conducted, but almost all of the studies have dealt with occupational stress; there is a lack of previous research on the potential association between presenteeism and working hours or shift work.

In general, presenteeism can cause a loss of productivity and adverse health effects [1,3,9-11]. Consequently, our results suggesting presenteeism due to long working hours, shift work, and occupational stress present an important perspective for industrial policy. We suggest that effective reductions in current long working hours and management of occupational stress can be a successful strategy for enhancing productivity and reducing presenteeism. We expect further reliable studies using objective data about workplace productivity and other adverse health effects of working hours, shift work, and occupational stress to arouse public awareness, and to provide evidence for policy making.

\section{Competing interests}

The authors declare that they have no competing interests.

\section{Author's contributions}

SHJ, HCK, and SGP designed the research. SHJ and BJL performed the statistical analysis and interpreted the data. SHJ and HCK wrote the manuscript. JHL, SHM and DYJ critically revised the manuscript. All authors read and approved the final manuscript.

\section{Acknowledgments}

This work was supported by INHA UNIVERSITY Research Grant.

Received: 2 September 2013 Accepted: 4 March 2014

Published: 24 March 2014

\section{References}

1. Loeppke R, Taitel M, Haufle V, Parry T, Kessler RC, Jinnett K: Health and Productivity as a Business Strategy: a Multiemployer Study. J Occup Environ Med 2009, 51(4):411-428.

2. Schultz $A B$, Edington DW: Employee Health and Presenteeism: a Systematic Review. J OccupRehabil 2007, 17(3):547-579.

3. Sanderson K, Cocker F: Presenteeism-Implications and Health Risks. Aust Fam Physician 2013, 42(4):172-175.
4. Hemp P: Presenteeism: at Work-but out of it. Harv Bus Rev 2004, 82(10):49,58,155

5. Kivimaki M, Batty GD, Hamer M, Ferrie JE, Vahtera J, Virtanen M, Marmot MG, Singh-Manoux A, Shipley MJ: Using Additional Information on Working Hours to Predict Coronary Heart Disease: a Cohort Study. Ann Intern Med 2011, 154(7):457-463.

6. Gustafsson K, Marklund S: Consequences of Sickness Presence and Sickness Absence on Health and Work Ability: a Swedish Prospective Cohort Study. Int J Occup Med Environ Health 2011, 24(2):153-165.

7. Bergstrom G, Bodin L, Hagberg J, Lindh T, Aronsson G, Josephson M: Does Sickness Presenteeism Have an Impact on Future General Health? Int Arch Occup Environ Health 2009, 82(10):1179-1190.

8. Taloyan M, Aronsson G, Leineweber C, Magnusson Hanson L, Alexanderson K, Westerlund H: Sickness Presenteeism Predicts Suboptimal Self-Rated Health and Sickness Absence: a Nationally Representative Study of the Swedish Working Population. PLOS One 2012, 7(9):e44721.

9. de Graaf R, Tuithof M, van Dorsselaer S, ten Have M: Comparing the Effects on Work Performance of Mental and Physical Disorders. Soc Psychiatry Psychiatr Epidemiol 2012, 47(11):1873-1883.

10. Lerner D, Adler DA, Rogers WH, Chang H, Lapitsky L, McLaughlin T, Reed J: Work Performance of Employees with Depression: the Impact of Work Stressors. Am J Health Promot 2010, 24(3):205-213.

11. Oh S, Jung K, Park J: The Association of Health Risks with Absenteeism and Presenteeism. Korean J Occup Environ Med 2007, 19(4):304-314. Korean.

12. Burton WN, Chen CY, Conti DJ, Schultz AB, Edington DW: The Association Between Health Risk Change and Presenteeism Change. J Occup Environ Med 2006, 48:252-263.

13. Uehata T: Long Working Hours and Occupational Stress-Related Cardiovascular Attacks Among Middle-Aged Workers in Japan. J Hum Ergol 1991, 20(2):147-153.

14. Nakamura K, Shimai S, Kikuchi S, Takahashi H, Tanaka M, Nakano S, Motohashi Y, Nakadaira H, Yamamoto M: Increases in Body Mass Index and Waist Circumference as Outcomes of Working Overtime. Occup Med 1998, 48(3):169-173.

15. Maruyama S, Morimoto K: Effects of Long Work Hours on Life-Style, Stress and Quality of Life Among Intermediate Japanese Managers. Scand J Work Environ Health 1996, 22(5):353-359.

16. Hayashi T, Kobayashi Y, Yamaoka K, Yano E: Effect of Overtime Work on 24-Hour Ambulatory Blood Pressure. J Occup Environ Med 1996, 38 (10):1007-1011.

17. Sokejima S, Kagamimori S: Working Hours as a Risk Factor for Acute Myocardial Infarction in Japan: case Control Study. BMJ 1998, 317:775-780.

18. Iwasaki K, Sasaki T, Oka T, Hisanaga N: Effect of Working Hours on Biological Functions Related to Cardiovascular System Among Salesmen in a Machinery Manufacturing Company. Ind Health 1998, 36:361-367.

19. Esquirol $Y$, Bongard V, Mabile $L$, Jonnier B, Soulat JM, Perret B: Shift Work and Metabolic Syndrome: Respective Impacts of job Strain, Physical Activity, and Dietary Rhythms. Chronobiol Int 2009, 26(3):544-559.

20. Karlsson B, Knutsson A, Lindahl B: Is There an Association Between Shift Work and Having a Metabolic Syndrome? Results from a Population Based Study of 27,485 People. Occup Environ Med 2001, 58(11):747-752.

21. Mohren DC, Jansen NW, Kant IJ, Galama J, van den Brandt PA, Swaen GM: Prevalence of Common Infections Among Employees Indifferent Work Schedules. J Occup Environ Med 2002, 44(11):1003-1011.

22. Sharifian A, Farahani S, Pasalar P, Gharavi M, Aminian O: Shift Work as an Oxidative Stressor. J Circadian Rhythms 2005, 3(1):15.

23. Mäki K, Vahtera J, Virtanen M, Elovainio M, Keltikangas-Järvinen L, Kivimäki M: Work Stress and new-Onset Migraine in a Female Employee Population. Cephalalgia 2008, 28(1):18-25.

24. Light KC, Turner JR, Hinderliter AL: Job Strain and Ambulatory Work Blood Pressure in Healthy Young men and Women. Hypertension 1992, 20(2):214-218.

25. Bosma H, Marmot MG, Hemingway H, Nicholson AC, Brunner E, Stansfeld SA: Low job Control and Risk of Coronary Heart Disease in Whitehall II (Prospective Cohort) Study. BMJ 1997, 314:558-565.

26. Karasek R, Baker D, Marxer F, Ahlbom A, Theorell T: Job Decision Latitude, job Demands, and Cardiovascular Disease: a Prospective Study of Swedish men. Am J Public Health 1981, 71(7):694-705.

27. Bourbonnais R, Brisson C, Moisan J, Vézina M: Job Strain and Psychological Distress in White-Collar Workers. Scand J Work Environ Health 1996, 22(2):139-145. 
28. Braun S, Hollander RB: Work and Depression Among Women in the Federal Republic of Germany. Women Health 1988, 14(2):3-26.

29. Williams RB, Barefoot JC, Blumenthal JA, Helms MJ, Luecken L, Pieper CF, Siegler IC, Suarez EC: Psychosocial Correlates of job Strain in a Sample of Working Women. Arch Gen Psychiatry 1997, 54:543-548.

30. Stansfeld SA, Fuhrer R, Head J, Ferrie J, Shipley M: Work and Psychiatric Disorder in the Whitehall II Study. J Psychosom Res 1997, 43(1):73-81.

31. Hellerstedt WL, Jeffery RW: The Association of job Strain and Health Behaviours in men and Women. Int J Epidemiol 1997, 26(3):575-583.

32. Green KL, Johnson JV: The Effects of Psychosocial Work Organization on Patterns of Cigarette Smoking Among Male Chemical Plant Employees. Am J Public Health 1990, 80(11):1368-1371.

33. Merrill RM, Aldana SG, Pope JE, Anderson DR, Coberley CR, Whitmer RW, Subcommittee HRS: Presenteeism According to Healthy Behaviors, Physical Health, and Work Environment. Popul Health Manag 2012, 15(5):293-301.

34. Ryu I, Jeong D, Kim I, Roh J, Won J: Association Between Job Stress, Psychosocial Well-Being and Presenteeism, Absenteeism: Focusing on Railroad Workers. Korean J Occup Environ Med 2012, 24(3):263-273. Korean.

35. Ministry of Employment and Labor: Chapter IV: Working Hours and Recess. In Labor Standard Act; 2012. http://www.moel.go.kr/english/ download_eng.jsp?type=\&file=(31)LABORSTANDARDSACT_2012.pdf.

36. Kim JE: Secondary analysis of Korean working conditions survey: Causes of Absenteeism due to Disease in Employed Women. In Occupational safety \& healthy research Institute. Korean: Korea Occupational Safety \& Health Agency; 2011:3-19.

37. Lund T, Labriola M, Christensen KB, Bu"ltmann U, Villadsen E: Physical Work Environment Risk Factors for Long Term Sickness Absence: Prospective Findings Among a Cohort of 5357 Employees in Denmark. BMJ 2006, 332:449-452.

38. Laaksonen M, Pitkäniemi J, Rahkonen O, Lahelma E: Work Arrangements, Physical Working Conditions, and Psychosocial Working Conditions as Risk Factors for Sickness Absence: Bayesian Analysis of Prospective Data. Ann Epidemiol 2010, 20(5):332-338.

39. Kobayashi T, Suzuki E, Takao S, Doi H: Long Working Hours and Metabolic Syndrome Among Japanese men: a Cross-Sectional Study. BMC Public Health 2012, 12:395.

40. Yang H, Schnall PL, Jauregui M, Su TC, Baker D: Work Hours and Self-Reported Hypertension Among Working People in California. Hypertension 2006, 48(4):744-750.

41. Solovieva S, Lallukka T, Virtanen M, Viikari-Juntura E: Psychosocial Factors at Work, Long Work Hours, and Obesity: a Systematic Review. Scand J Work Environ Health 2013, 39(3):241-258.

42. Virtanen M, Ferrie JE, Gimeno D, Vahtera J, Elovainio M, Singh-Manoux A, Marmot MG, Kivimaki M: Long Working Hours and Sleep Disturbances: the Whitehall II Prospective Cohort Study. Sleep 2009, 32(6):737-745.

43. Kim I, Kim H, Lim S, Lee M, Bahk J, June K, Kim S, Chang WJ: Working Hours and Depressive Symptomatology Among Full-Time Employees: Results from the Fourth Korean National Health and Nutrition Examination Survey (2007-2009). Scand J Work Environ Health 2013, 39(5):515-520.

44. Virtanen M, Ferrie JE, Singh-Manoux A, Shipley MJ, Stansfeld SA, Marmot MG, Ahola K, Vahtera J, Kivimäki M: Long Working Hours and Symptoms of Anxiety and Depression: a 5-Year Follow-up of the Whitehall II Study. Psychol Med 2011, 41(12):2485-2494.

45. Nakata A, Ikeda T, Takahashi M, Haratani T, Fujioka Y, Fukui S, Swanson NG, Hojou M, Araki S: Sleep-Related Risk of Occupational Injuries in Japanese Small and Medium-Scale Enterprises. Ind Health 2005, 43(1):89-97.

46. Metlaine A, Leger D, Choudat D: Socioeconomic Impact of Insomnia in Working Populations. Ind Health 2005, 43(1):11-19.

47. Costa G: Shift Work and Occupational Medicine: an Overview. Occup Med 2003, 53:83-88.

48. Bockerman P, Laukkanen E: What Makes you Work While you are Sick? Evidence from a Survey of Workers. Eur J Public Health 2010, 20(1):43-46.

49. Sangheon L, Deirdre MC, Messenger JC: Work Schedules in the Service Sector, Working Time Around the World: Trends in Working Hours, Laws, and Policies in a Global Comparative Perspective. Abingdon: Routledge; 2007:96-100.

50. Kim J, Park S, Kim D, Kim H, Leem J, Lee E, Lee D, Lee J: Absence and Early Leave Status due to Job Stress and its Relationship to Job Stress Factors According to the Korean Occupational Stress Scale among Workers in Small and Medium Scale Industry. Korean J Occup Environ Med 2009, 21(2):107-114. Korean.
51. Sundquist J, Ostergren PO, Sundquist K, Johansson SE: Psychosocial Working Conditions and Self-Reported Long-Term IIIness: a Population-Based Study of Swedish-Born and Foreign-Born Employed Persons. Ethn Health 2003, 8(4):307-317.

52. Moon-Hee J, Young-Mi L, Mikako A: Stress and Presenteeism in Workers of Small and Medium Enterprises. Korean J Occup Environ Med 2007. 19(1):47-55.

53. Boles M, Pelletier B, Lynch W: The Relationship Between Health Risks and Work Productivity. J Occup Environ Med 2004, 46(7):737-745.

54. Elstad JI, Vabø M: Job Stress, Sickness Absence and Sickness Presenteeism in Nordic Elderly Care. Scand J Public Health 2008, 36(5):467-474.

55. Demerouti E, Le Blanc PM, Bakker AB, Schaufeli WB, Hox J: Present but Sick: a Three-Wave Study on job Demands, Presenteeism and Burnout. Career Dev Int 2009, 14(1):50-68.

56. Aronsson G, Gustafsson K, Dallner M: Sick but yet at Work: an Empirical Study of Sickness Presenteeism. J Epidemiol Community Health 2000, 54(7):502-509.

57. Aronsson G, Gustafsson K: Sickness Presenteeism: Prevalence, Attendance-Pressure Factors, and an Outline of a Model for Research. J Occup Environ Med 2005, 47(9):958-966.

58. McKevitt C, Morgan M, Dundas R, Holland WW: Sickness Absence and 'Working through' Illness: a Comparison of two Professional Groups. J Public Health Med 1997, 19:295-300.

59. Crout AL, Chang E, Cioffi J: Why do Registered Nurses Work When ill. J Nurs Adm 2005, 35:23-28.

doi:10.1186/2052-4374-26-6

Cite this article as: Jeon et al: Association among Working Hours, Occupational Stress, and Presenteeism among Wage Workers: Results from the Second Korean Working Conditions Survey. Annals of Occupational and Environmental Medicine 2014 26:6.

\section{Submit your next manuscript to BioMed Central and take full advantage of:}

- Convenient online submission

- Thorough peer review

- No space constraints or color figure charges

- Immediate publication on acceptance

- Inclusion in PubMed, CAS, Scopus and Google Scholar

- Research which is freely available for redistribution 